Revista Eletrônica do Mestrado em Educação Ambienta1

Programa de Pós-Graduação em Educação Ambiental

\title{
Derivas da ecogovernamentalidade: cartografando contradispositivos espácio- temporais e máquinas estéticas
}

\author{
Adalberto Ferdnando Inocêncio ${ }^{1}$ \\ Universidade Estadual de Londrina \\ https://orcid.org/0000-0002-2659-3073
}

\begin{abstract}
Resumo: Concebendo a internet como tecnologia de época, buscaram-se materialidades discursivas que pudessem ser entendidas como estéticas da existência, no que diz respeito às relações que estabelecem com o meio ambiente no tempo presente. O objetivo central foi o de colocar em evidência quais são as tecnologias que estão em jogo na experimentação de práticas de liberdade. Adotou-se a cartografia como pista de um método que possibilita identificar tais processos e, no recorte analítico considerado, foram discutidos os contradispositivos espaciotemporais e as máquinas estéticas reconhecidas na materialidade discursiva presente nas obras dos artistas brasileiros Roberta Carvalho e Eduardo Srur. Lidas como territórios existenciais, as obras se constituem por narrativas que escapam de ecologias policialescas e normativas incitadas pela ecogovernamentalidade.
\end{abstract}

Palavras-chave: Crise ambiental. Território existencial. Obras de arte.

\section{Derivadas de la ecogobernabilidad: cartografía de contradispositivos espacio- temporales y máquinas estéticas}

Resumen: Al concebir internet como una tecnologia de la época, buscamos materialidades discursivas que puedan intenderse como uma estética de la existência, com respecto a las relaciones que se llevan a cabo com el medio ambiente em la actualidad. El objetivo central era destacar qué tecnologias están em juego em la experimentación de las prácticas de libertad. La cartografia se adoptó como una pista para um método que responde a los procesos $\mathrm{y}$, em el marco analítico considerado, se discuten los contradispositivos espacio-temporales y las máquinas estéticas, reconocidos em la materialidad discursiva presente em las obras de los artistas brasileños Roberta

\footnotetext{
${ }^{1}$ Doutor em Ensino de Ciências pela Universidade Estadual de Londrina (UEL). Professor colaborador na Universidade Estadual de Maringá (UEM). e-mail: afinocencio88@gmail.com

Rev. Eletrônica Mestr. Educ. Ambient. Rio Grande, Dossiê temático "Imagens: resistências e criações cotidianas", p. 430-449, jun. 2020. E-ISSN 1517-1256
} 
Carvalho y Eduardo Srur. Leídos como territorios existenciales, las obras están constituídas por narrativas que escapan a la policía y a las ecologías normativas incitadas por la ecogobernabilidad.

Palabras clave: Crisis ambiental. Territorio existencial. Obras de arte.

\title{
Derives from ecogovernamentality: cartographing spacio-temporal contradisvises and aesthetic machines
}

\begin{abstract}
Conceiving the internet as a actual technology, discursive materialities were sought that could be understood as aesthetics of existence, with regard to the relation ships that are undertaken with the environment as the presente time. The central objective was to highlight which technologies are at play in experimenting with freedom practices. Adopted Cartography as a clue to a method that responds to processes and, in the analytical framework considered, the spatiotemporal counter-devices and aesthethic machines, recognized in the discursive materiality present in the Works of brazilian artists Roberta Carvalho and Eduardo Srur. Read as existencial territories, the Works are constituted by narratives that escape police and normative ecologies incited by ecogovernmentality.

Keywords: Environmentalcrisis. Existentialterritory. Works of art.
\end{abstract}

\section{Introdução}

O presente artigo é resultado de uma tese de doutoramento que pretendeu investigar de quais maneiras a proliferação discursiva da crise ambiental que emergiu nas últimas décadas se relaciona com a construção das subjetividades no tempo presente. Admitindo que frente a esta crise a vida se prolifera em movimentos intensivos de recusa das verdades estabelecidas e das práticas cristalizadas, o objetivo central desta investigação foi o de colocar em evidência quais são as tecnologias que estão em jogo na experimentação de liberdades, bem como os modos possíveis de se verificar tensionamentos individuais ou coletivos diante das racionalidades de governo ou tecnologias de poder que se encontram em vigor.

Por meio do olhar teórico das investigações foucaultianas visou-se cartografar os modos pelos quais sujeitos constroem, para si, territórios outros, entendidos como formas de vida não modalizadas pela ecogovernamentalidade e pelas relações que esta enseja por meio da macropolítica. No recorte aqui apresentado, selecionaram-se as materialidades discursivas cartografadas em sua expressão artística num espaço estratégico.

Assumiu-se como hipótese que, por meio das tecnologias de $\mathrm{si}^{2}$, é possível que algumas subjetividades construam processos de recusa das formas de vida pensadas previamente em gabinetes que se encontram distantes dos acontecimentos microfísicos e

${ }^{2}$ Conceito apresentado e discutido a seguir.

Rev. Eletrônica Mestr. Educ. Ambient. Rio Grande, Dossiê temático "Imagens: resistências e criações cotidianas", p. 430-449, jun. 2020. E-ISSN 1517-1256 
micropolíticos. No recorte que ora se prioriza, é levada em conta a criação de contradispositivos espaciotemporais e de máquinas estéticas, conceitos delineados por Pelbart (2016) e Guattari (2012), respectivamente. Tanto os contradispositivos, como as máquinas delineiam o que se considera um território existencial, uma vez que se caracterizam por processos de subjetivação em trânsito. Esses territórios são entendidos como movimentos de resistência aos poderes totalitários e objetivantes da ecogovernamentalidade, conceito formulado por Malette (2011) e apresentado em uma seção a seguir.

Em vez de esquadrinhar um percurso caracterizado por fases nítidas que representassem contornos acentuados de começo, meio e fim, adotou-se a cartografia (DELEUZE, 2013; PASSOS, KASTRUP, ESCÓSSIA, 2015) como abordagem metodológica. A cartografia permite acentuar os contornos de um diagrama, isto é, o conjunto de relações de formas e de forças que nos convoca a sermos o que somos no tempo presente. O conceito foucaultiano de estética da existência funcionou como operador na escolha das materialidades discursivas encontradas, permitindo analisá-las em suas recorrências e descontinuidades.

\section{Da governamentalidade à ecogovernamentalidade}

Apesar de a analítica da governamentalidade despontar desde o século XVI, recebeu importância ao final da vida de Foucault, figurando, com mais ênfase, nos seus últimos cursos lecionados no Collège de France (1975-1980). Assim como a disciplina não superou a soberania, é importante situar que por governamentalidade não se deve entender uma modalidade que superou tanto o poder disciplinar como o biopoder.

No fortalecimento do Estado nação como instância regulatória, Foucault (2008) inscreveu o horizonte da biopolítica. Na verdade, o nascimento do Estado moderno só chegou a ser possível quando a "governamentalidade ganhou o caráter de uma prática política calculada e refletida" (FOUCAULT, 2008, p. 219). Nesse âmbito, não se governam apenas os indivíduos em dimensão anátomo-política, individual e, portanto, disciplinar, mas se passa a reconhecer a população, conceito criado a fim de atender um novo regime de regulação, desta vez, em termos de taxas de natalidade, mortalidade, imigração e emigração.

Rev. Eletrônica Mestr. Educ. Ambient. Rio Grande, Dossiê temático "Imagens: resistências e criações cotidianas", p. 430-449, jun. 2020. E-ISSN 1517-1256 
Neste entendimento, a governamentalidade expandiu o sentido usual de governo, como instância superior, para todo ato minucioso exercido pelo cidadão comum, individual ou coletivamente. Por governamentalidade, Foucault (2008, p. 143-144) definiu “o conjunto constituído pelas instituições, procedimentos, análises e reflexões, os cálculos e as táticas que permitem exercer essa forma bem específica [...] de poder que tem por alvo principal a população". No mesmo curso, o filósofo complementa: "a análise da governamentalidade implica que 'tudo é político"' (FOUCAULT, 2008, p. 287). Se tudo é político, as resistências ou contracondutas, como ele também conceitua, são formas de recusa e, portanto, componentes da governamentalidade. Esse movimento, de que se pode produzir diferenças "no interior" mesmo das relações de poder, é anunciado no curso Segurança, Território, População.

Destaca-se, ainda, outra definição importante da mesma terminologia, desta vez presente em As Técnicas de si (FOUCAULT, 2014a, p. 266): "Eu chamo 'governamentalidade' o encontro entre as técnicas de dominação exercidas sobre os outros e as técnicas de si”. As técnicas de si são um conjunto de práticas ligadas ao que ele chamará de "artes da existência". É por meio delas que se pode interrogar-se sobre a própria conduta, impedir que se conforme sobre ela e governar-se a si próprio nas propostas de ascese: "a análise das relações de poder e de suas tecnologias permitia focalizá-las como estratégias abertas, escapando à alternativa de um poder concebido como dominação" (FOUCAULT, 2014b, p. 9). Destacam-se diferentes definições desse mesmo conceito, pois ambas visibilizam que a vida não somente se curva às táticas hegemônicas, mas também escapa às suas técnicas de dominação, acentuação imprescindível para as análises consideradas neste ensaio.

Se, por um lado, a biopolítica foi caracterizada como estratégia das sociedades liberais, nas sociedades neoliberais consagra-se a ecopolítica (VEIGA-NETO, 2014) e a ecogovernamentalidade ou, ainda, governamentalidade verde (MALETTE, 2011). Esses conceitos só aparecem devido a uma condição de existência histórica, marcada por um progressivo fenômeno de desfronteirização contemporânea, que não nega ou se atrita com os efeitos da biopolítica, mas os amplia para um território, que opera pelo caráter controlador e utilitarista das relações que se estabelecem entre as vidas humanas e o meio ambiente na medida em que um arsenal tecnológico age como mediador desta relação. Ecopolítica e ecogovernamentalidade estariam em sintonia com as técnicas de dominação, apresentadas anteriormente, uma vez que "conduzem condutas". Essas novas formas de Rev. Eletrônica Mestr. Educ. Ambient. Rio Grande, Dossiê temático "Imagens: resistências e criações cotidianas", p. 430-449, jun. 2020. E-ISSN 1517-1256 
funcionamento do poder arrastam consigo as anteriores, de modo que não só "[...] a ecopolítica não desloca a importância até agora conferida à biopolítica como, também, amplia do humano para o planetário, o papel conferido a vida" (VEIGA-NETO, 2014, p. 40).

Como práticas de governo, tanto a ecopolítica, como a ecogovernamentalidade se consolidam a partir da segunda metade do século passado e na inflexão deste milênio, apoiando-se na crença de que é preciso acompanhar todos os fluxos planetários, monitorando o planeta com o auxílio de técnicas e políticas desenvolvidas especificamente para tal função o que, por sua vez, consagrou a modalidade de um capitalismo continuado (SIQUEIRA, 2016).

Apresentados esses conceitos, ressalta-se que a problemática desta investigação não esteve assentada na discussão que se faz sobre as políticas internacionais e nacionais, pois a visibilidade que estas assumem para a questão ambiental é um reconhecimento do que vem sendo chamado a atenção pelos movimentos ambientalistas. A crítica reside no esgotamento de potencialidades que essas políticas são capazes de promover, quando não apenas oferecem, mas também incitam e persuadem as condutas orientadas por um quadro político caracterizado por projetos rígidos e acabados, decididos à distância da escala microfísica e micropolítica. Por esses termos, alude-se às esferas da vida cotidiana, às singularidades próprias de cada um, "ao calor dos dias e das trocas" nas pluralidades que se expressam nos modos de se relacionar com o meio ambiente. Admite-se, então, que se o mundo é composto por multiplicidades em trânsito, "não há um sentido único a ser desvelado por uma razão privilegiada, mas tantos sentidos quantas forem às configurações de forças dos quais derivam" (GODOY, 2008, p. 46).

Tais prescrições são atualizadas nos modos de vida exauridos pelas disposições que se pautam no que se deve ou não fazer, no que se pode ou não fazer, ao se relacionar com o ambiente, uma vez que obedecemos a um modelo de perfeição e pureza que arrasta essas categorias, "pois frente à natureza a ser conservada nunca se faz o bastante, nunca se é bom o bastante, nunca se sabe o bastante e todo cuidado permanece sendo pouco" (GODOY, 2007, p. 125). Por isso, "a história contada pela ecologia é a da subsunção da vida e do pensamento à forma do verdadeiro, o que a torna o arauto das prescrições e das medidas profiláticas que nos permitirão viver" e, ao alegar uma derrota iminente, "ela aponta o 'cada um de nós', distribuindo, assim, a responsabilidade e a culpa por uma vida que fracassa, pelo pior dos mundos" (GODOY, 2007, p. 102). Ao reconhecer que existem Rev. Eletrônica Mestr. Educ. Ambient. Rio Grande, Dossiê temático "Imagens: resistências e criações cotidianas", p. 430-449, jun. 2020. E-ISSN 1517-1256 
culpados pela morte do mundo, um imenso diagrama de saberes e poderes, de formas e de forças, é posto em circulação pela ecogovernamentalidade e pela ecopolítica como regimes de nosso tempo.

$\mathrm{Na}$ sequência, apresentam-se alguns componentes desse diagrama, dando ênfase aos centralizados no amortecimento subjetivo planejado para os espaços de circulação, dentre os quais, o citadino.

\section{Uma face da ecogovernamentalidade: a construção do meio como território}

É imprescindível situar que, no contexto da ecogovernamentalidade e da ecopolítica, o conceito de (meio) ambiente aparece carregado de outras forças e efeitos de sentido diferentes daqueles encontrados em outros momentos da história. Nos cursos lecionados no Collège de France, é possível identificar algumas passagens que aludem à noção de meio como um dos elementos que participam do cálculo de segurança, uma vez que assinala a distância da ação de um corpo sobre outro, ao movimento dos corpos e suas mútuas interferências. Além disso, na seção Situação dos cursos, ao final de Segurança, Território, População, Michel Senellart aponta que Foucault discriminava três grandes domínios de intervenção da biopolítica no fim do século XVIII e no início do século XIX, sendo a terceira delas "[...] as relações entre os homens, como seres vivos, e seu meio, através, essencialmente, do problema da cidade" (FOUCAULT, 2008, p. 516, grifo meu).

Deste modo, à luz da biopolítica, uma prática de proteção dos limites da cidade entra em vigor durante o século XVIII: as tecnologias de poder passam a fazer a leitura da peste não somente sob o viés da purificação, mas da ameaça à produtividade do corpo saudável, hábil para o trabalho e produção (FOUCAULT, 2001). Nesse limiar, um arraste grosseiro da separação espacial vai cedendo aos mecanismos de vigilância, de exame e de classificação, buscando intensificar um controle interno da epidemia na totalidade das cidades. É nessa tríade segurança-território-população que "o meio, milieu, teve um papel decisivo na construção dessas técnicas de segurança na biopolítica, pois os cálculos dos perigos e riscos possíveis envolviam qualidades dos locais onde estava a população" (CARNEIRO, 2012, p. 3).

Num trecho específico, Michel Foucault discute a noção de meio pensando-a como um território em potencial:

Rev. Eletrônica Mestr. Educ. Ambient. Rio Grande, Dossiê temático "Imagens: resistências e criações cotidianas", p. 430-449, jun. 2020. E-ISSN 1517-1256 
O espaço em que se desenrolam as séries de elementos aleatórios é, [...] o que chamamos de meio [...] O que é o meio? É o que é necessário para explicar a ação à distância de um corpo sobre outro. É, portanto, o suporte e o elemento de circulação de uma ação. É, portanto, o problema circulação e causalidade que está em questão nessa noção de meio. [O conceito] está presente na maneira como os urbanistas procuram refletir e modificar o espaço urbano. Os dispositivos de segurança trabalham, criam, organizam, planejam um meio [...] O meio é um conjunto de dados naturais, rios, pântanos, morros, é um conjunto de dados artificiais, aglomeração de indivíduos, aglomeração de casas, etc. (FOUCAULT, 2008 , p. 27-28, grifo nosso).

Este trecho evidencia uma analítica de poder que não se resume ao esquadrinhamento de uma população em um território, mas em sua estratificação gradual em um meio (ambiente). Nesse sentido, Pelbart (2017) atualiza a noção de governamentalidade, argumentando que a atual conjuntura se caracteriza menos por uma instituição ou alguém que manda, e mais por mecanismos de "condução de condutas de uma população, que configuram um ambiente, um meio", portanto, "trata-se de agir sobre o meio, pois é nesse plano que vemos instaurar-se uma governança a partir dos equipamentos urbanos que organizam a vida tecnológica e mercantilmente" (PELBART, 2017, p. 97).

Se o meio passa a ser lido como um espaço de potencial distância entre os corpos em circulação, é preciso que se desenvolva, progressivamente, um conjunto de técnicas capazes de mapeá-lo em seus complexos desenhos no território. Definido o meio (ambiente) naquilo que se faz circulação, é preciso pôr em andamento mecanismos capazes de regularizar o máximo possível os efeitos que o atravessam. Estabelecida a relação de meio como um território que deve ser mapeado pelas forças totalitárias de Estado é que passa a fazer sentido o desenvolvimento e a atuação de dispositivos diplomático-militares, de segurança planetária, de segurança climática, das tecnologias espaciais, para ficar nesses exemplos.

\section{A cartografia como hódos-metá: acentuando os contornos de um corpus analítico}

Em vez de regras e protocolos, o método cartográfico está mais próximo da composição de pistas que, em conjunto, contribuirão para a construção de um diagrama que será analisado. De acordo com Passos, Kastrup e Escóssia (2015), no delineamento da cartografia, há pistas a serem seguidas, de modo que não se trata de uma sequência linear

Rev. Eletrônica Mestr. Educ. Ambient. Rio Grande, Dossiê temático "Imagens: resistências e criações cotidianas", p. 430-449, jun. 2020. E-ISSN 1517-1256 
de passos, mas de escolhas e de usos que se fazem no acompanhamento de um processo orientado pela atenção, necessidade e, até, sensibilidade do cartógrafo. Trabalhar com a cartografia implica elaborar um diagrama, esboçado pela proposição de coordenadas capazes de acoplar os complexos saberes-poderes.

Ao ler a obra de Foucault, Deleuze (2013, p. 44) elabora conceitualmente o diagrama do seguinte modo: "O diagrama não é mais o arquivo, auditivo ou visual, é o mapa, a cartografia, co-extensiva a todo o campo social. É uma máquina abstrata”. Nesta definição, o diagrama se aproxima de funções e matérias informes, ignorando toda distinção de forma entre um conteúdo e uma expressão, entre uma formação discursiva e uma formação não discursiva, aproximando-se da noção de dispositivo.

Buscando um método que estivesse em sintonia com o caráter processual de investigação, encontrou-se em Passos, Kastrup e Escóssia (2015) elementos para a construção do percurso metodológico. Ao invés de vários a priori, optam por um instrumental que se assemelha ao que Foucault já previra em sua obra, a saber, funcionar como uma caixa de ferramentas. Acompanhar um processo está mais próximo ao movimento arqueogenealógico que escava os ditos e os saberes e os situa na posição histórica de sua condição de existência.

No método cartográfico “[...] é o primado do caminhar que traça, no percurso, suas metas" (PASSOS; BARROS, 2015, p. 17), isto é, não se trata de caminhar para alcançar as metas prefixadas do metá-hódos (metá - reflexão, raciocínio, verdade; hódos - caminho, direção), por isso, faz mais sentido a inversão hódos-metá. Disso decorre que os objetivos foram construídos durante o processo de observação, não estando previamente estabelecidos. Nesse sentido, o início dessa investigação não se caracterizou pela procura de materialidades discursivas a respeito de tecnologias referentes aos espaços que servem de trânsito. Antes, muniu-se do conceito de ecogovernamentalidade como reconhecimento de um poder vigente, capaz de encetar diversos setores da sociedade, dentre eles o de planejamento urbano e rural, mas, também, as áreas litorâneas, florestais e ribeirinhas.

No início dessa pesquisa, a atenção assumia um caráter "flutuante" acerca das materialidades discursivas que seriam contempladas como corpus analítico. Um dos objetivos da cartografia é "desenhar a rede de forças à qual o objeto ou fenômeno em questão se encontra conectado, dando conta de suas modulações e de seu movimento permanente. Para isso é preciso, num certo nível, se deixar levar por esse campo coletivo de forças" (BARROS; KASTRUP, 2015, p. 57). Nesse momento, a preocupação se dá no Rev. Eletrônica Mestr. Educ. Ambient. Rio Grande, Dossiê temático "Imagens: resistências e criações cotidianas", p. 430-449, jun. 2020. E-ISSN 1517-1256 
conhecimento de fragmentos desconexos - textos que enredam a outros textos num movimento vasto de conexões. Trata-se de um momento em que "a atenção não busca algo definido, mas torna-se aberta ao encontro" (KASTRUP, 2015, p. 38). Encontro, aqui, não significa somente o conhecimento e o contato com os textos, mas reconhecê-los - nas relações de poder, em sua textura, memória e experiência imanente - em seu caráter de contraconduta e resistência e, por isso mesmo, em seu potencial estético de análise.

Haja vista que a internet é reconhecidamente a máquina de nossos tempos (DELEUZE, 1992), foram selecionados elementos discursivos, textuais e imagéticos, disponíveis em páginas diversas da internet: textos jornalísticos digitais, matérias de plataformas educacionais, páginas profissionais de artistas, dentre outras, compondo um conjunto material de possíveis elementos analíticos. Não foram fixadas de antemão categorias textuais para a investigação, priorizou-se áreas distintas que pudessem ser encetadas pelas táticas da ecogovernamentalidade.

Passos, Kastrup e Escóssia (2015) indicam, ainda, que o funcionamento da atenção no trabalho do cartógrafo é orientado por um tipo de bússola. $\mathrm{Na}$ imersão por uma série de textos - enunciados, discursos e relações de força - foram selecionados aqueles que se caracterizaram como estéticas da existência construídas em um formato diferente das relações agenciadas pela ecogovernamentalidade. Tratam-se de textualidades que se caracterizam por estéticas da existência, ou práticas de liberdade, construídas em oposição aos agenciamentos do Estado ou mercado (FOUCAULT, 2014a).

Foram mantidos os elementos foucaultianos analíticos das fases arqueológica e genealógica - a análise dos saberes e poderes subjacentes às suas respectivas condições históricas de existência, suas descontinuidades e estridências - buscando identificar essas estéticas da existência. Nos elementos materiais selecionados, identificaram-se processos estéticos de diversas formas, também operando em setores diversos: textos no âmbito educativo e jornalísticos também foram selecionados no estudo mais amplo que deu origem a esse recorte, sendo que, aqui, foram mantidas para análise as obras artísticas. Por utilizarem tecnologias capazes de operacionalizar campos potentes de pensamento, os resultados dessas estéticas foram chamados de territórios existenciais nesta investigação.

Por fim, para esquadrinhar este eixo analítico, importa anunciar que se optou por setores não serializados da arte, isto é, da arte majoritária, institucionalizada nos territórios que a validam como tal: os museus, as bienais, os grandes circuitos das exposições e dos críticos da arte. Adotou-se uma perspectiva de se pensar a arte com Guattari (2012, p. 106), Rev. Eletrônica Mestr. Educ. Ambient. Rio Grande, Dossiê temático "Imagens: resistências e criações cotidianas", p. 430-449, jun. 2020. E-ISSN 1517-1256 
para quem ela "não é somente a existência de artistas patenteados, mas também de toda uma criatividade subjetiva que atravessa os povos e as gerações oprimidas, os guetos, as minorias...".

\section{Os rostos de Roberta Carvalho e os mapas de plástico de Eduardo Srur: acentuando os contornos de estéticas da existência}

Inicia-se essa seção analítica pela obra da artista paraense Roberta Carvalho. A obra apresentada e discutida aqui é decorrente de um projeto denominado Symbiosis e está referenciada em um texto que intercala produções escritas e imagéticas. A escolha deste componente se deu pelo modo no qual a artista brasileira coaduna arte contemporânea, tecnologia e saberes tradicionais.

As expressões artísticas da artista perfilam-se em composições visuais (Figura 1) que ganharam forma nas copas de árvores da ilha Combú, localizada em Belém do Pará (PA). Em tais composições, estão pixelizados rostos de membros da população ribeirinha que habitam essa região e navegam de barco da ilha para o continente. Ante essa produção, questionou-se: De que modo a instalação dessa artista paraense é capaz de "borrar" os feixes da ecogovernamentalidade como modalidade de poder de nossos tempos? Que efeitos de sentido (sobretudo éticos) têm esses rostos na plataforma cibernética da internet?

Figura 1: Fotografias de projeções de rostos de membros da população ribeirinha, parte integrante do projeto Symbiosis, da artista visual paraense Roberta Carvalho.

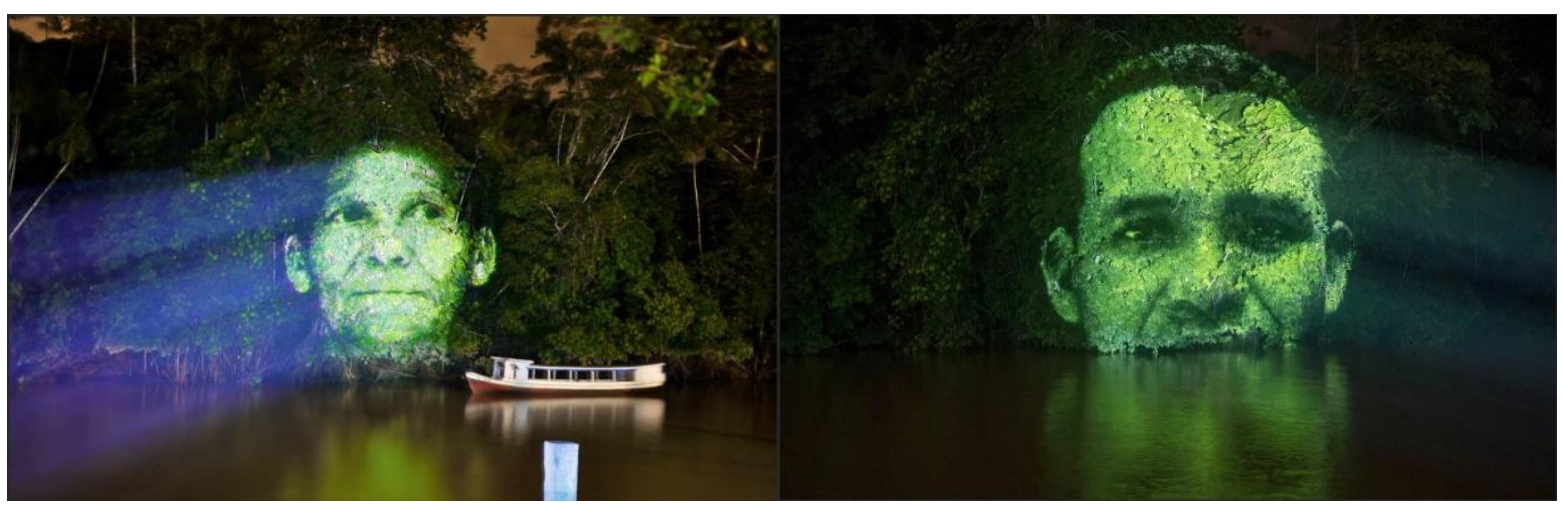

${ }^{1}$ Fonte: http://artenaescola.org.br/boletim/materia.php?id=77410.

A menção ao rosto aparece logo na fase arqueológica, sobretudo no último capítulo de As palavras e as coisas (FOUCAULT, 2007, p. 536), quando o filósofo buscou

Rev. Eletrônica Mestr. Educ. Ambient. Rio Grande, Dossiê temático "Imagens: resistências e criações cotidianas", p. 430-449, jun. 2020. E-ISSN 1517-1256 
demonstrar que o homem, como um "rosto de areia", é uma figura recente na história do ocidente, isso é, ele aparece como objeto ${ }^{3}$ de saberes na dobradiça do período clássico para o período moderno do século XVIII. Quando Foucault (2007) "dá rosto" ao homem, é, antes, para torná-lo uma categoria até então inexistente no campo dos saberes.

Quando a artista Roberta Carvalho "dá rosto" a alguns habitantes da população ribeirinha paraense é para instaurá-los num tempo-espaço que talvez não os reconhecesse como entes que ali habitam. Uma das potências criadoras de Roberta Carvalho é a de selecionar rostos não contemplados nos vetores hegemônicos dos modos de produção das subjetividades dominantes, daí a noção de instauração fazer sentido na analítica dessa obra. Ao cumprir certos requisitos de estilo, a obra de arte é passível de instauração (ROLNIK, 2002). A própria definição da artista visual ressalta a instauração singular desta obra, especificamente: entre a folhagem marrom e verde, "essas fisionomias evocam questões como memória e identidade dos povos amazônicos e suscitam ainda outro debate interessante: o de que a tecnologia pode aproximar a arte do espaço público" (ESCOLA, 2018, s/p.).

Como a obra incita a memória, a noção de instauração de Pelbart (2017) se expande: além de sujeitos, faz-se possível instaurar lugares e percursos. Marcos Reigota e Bárbara do Prado (2008, p. 13) destacam a importância das legitimações e divulgações das práticas sociais e pedagógicas cotidianas de inúmeros anônimos, haja vista que "os narradores/as constroem não só suas subjetividades e especificidades, mas elaboram e interpretam o local e o tempo em que vivem". No caso específico do rosto desses ribeirinhos, instaura-se, sobretudo, entes indissociáveis da paisagem que lhes serve como anteparo, haja vista que se sabe que essa população nativa desempenha um papel fundamental na manutenção da biodiversidade desta localidade. É o que vem sendo tratado pelo conceito de Sociobiodiversidade no âmbito da macropolítica. Em efeitos de sentido, a artista acaba por narrar esse mesmo conceito, só que pelo uso da linguagem artística e numa abordagem micropolítica, uma vez que arrasta uma população minoritária frente à varredura da política brasileira e das luzes maiores de uma maquinaria que os apaga.

O que esses autores clamam é que a busca por um processo mais democrático de habitar um local e toda a sua complexidade exige que, no interior dos distantes gabinetes, o cidadão citadino elaborador de projetos seja capaz de levar em conta as "leituras de

\footnotetext{
${ }^{3}$ Relação que permitiu o nascimento de saberes (ou disciplinas) enredados às Ciências Humanas, como a psicologia e a psiquiatria, para ficar nesses exemplos.

Rev. Eletrônica Mestr. Educ. Ambient. Rio Grande, Dossiê temático "Imagens: resistências e criações cotidianas", p. 430-449, jun. 2020. E-ISSN 1517-1256
} 
mundo" sobre diversos aspectos que fazem o Brasil contemporâneo, pela observação atenta dos anônimos envolvidos cotidianamente na construção de uma sociedade justa [...]" (REIGOTA; PRADO, 2008, p. 13). Nessa leitura, a arte de Roberta Carvalho é capaz de tensionar esse anonimato.

Ao "rostificar" uma superfície que tende a ser esquecida pela densidade da paisagem, este ato arrasta consigo um feixe de singularidade producente de um movimento ético que também envolve as tecnologias do olhar, a fim de reconhecer práticas realizadas por aqueles que estão nas margens, como as populações ribeirinhas ou extensionistas rurais. Reigota e Prado (2008) ressaltam que, no adensamento das matas, processos de implementação de sistemas Agroflorestais, como os utilizados pelo manejo de açaizal em São João do Pacuí (MG), estão longe de serem reconhecidos como saberes verdadeiros, dada a hegemonia de práticas centralizadoras provenientes das próprias instituições de ensino, do Partido Verde ou de movimentos como o Greenpeace.

O que está em questão nessa obra são existências que ganham aderência, seres solicitudinários, possibilitando universos que adquirem um tipo de registro na memória. É, sobretudo, uma aposta ética, pois também "multiplica, ao infinito, as 'embreagens existenciais', acedendo a universos criativos mutantes" (PELBART, 2016, p. 82). A existência - de um povo, uma cultura, uma materialidade - não é da ordem da dicotomia metafísica: existe ou não existe, mas da ordem das intensidades, operando por limiares qualitativos provenientes de certos territórios ou universos que ganharam algum contorno (literalmente, neste caso).

Como efeito dessa obra, o que se considera por "rostificação" é menos a figura de um rosto pixelizado nas copas das árvores decorrente de um disparo de canhão de fótons em si, mas sua capacidade imanente de dar forma a protosubjetividades (PELBART, 2016; 2017). Como também anunciou Guattari (2012, p. 118): “não existe trabalho algum que incida sobre as formas materiais que não presentifique entidades imateriais". Ainda que a artista instaure protosubjetividades sem a ambição de uma universalização ou salvacionismo, sua obra propõe uma "varredura" do lugar, mesclando elementos éticopolíticos, no sentido de que dão visibilidade (sobretudo de forma política) a entes que pedem passagem.

A noção de tecnologia que permeia essas composições, por mais que se componha de aparatos mecânicos e elétricos, disparadores de fótons, ao ganhar um tom sensível, também se aproxima de uma técnica de si. Há uma passagem do sensível como um de seus Rev. Eletrônica Mestr. Educ. Ambient. Rio Grande, Dossiê temático "Imagens: resistências e criações cotidianas", p. 430-449, jun. 2020. E-ISSN 1517-1256 
objetivos: "No caso do meu projeto, a natureza é a hospedeira da arte. A árvore não é apenas um anteparo para um vídeo ou uma imagem, mas se constrói também como obra", e complementa: "Quis que as pessoas refletissem sobre a relação entre identidade e natureza e também entre arte e tecnologia" (ESCOLA, 2018, s/p). Ao intentar provocar um modo de olhar, a artista também cria uma tecnologia que permite que indivíduos efetuem operações em suas almas, pensamentos, condutas e modos de ser.

Dando continuidade à analítica das tecnologias identificadas em sua potência criadora, concebem-se, também, as obras de Eduardo Srur. O artista paulistano se tornou referência na cidade e no país porque realiza intervenções no espaço urbano, cuja potência é de mobilizar o espectador. A escolha pela análise de algumas de suas obras ${ }^{4}$ residiu em sua capacidade estética de promover incômodos com relação ao modo de existência anestesiado - pois alguns processos que caracterizam a cinza espacialidade da urbe tornaram-se tão comuns, que nossos mecanismos ópticos permitem-nos transitar por eles naturalizando o que poderia não ser naturalizado - por meio do qual transeuntes percorrem espaços citadinos.

O aperfeiçoamento das propostas do artista o levou a focar sua produção num tripé erigido por questões éticas, ambientais e arquitetônicas, como aparecem em seu projeto PETS (Figura 2). Trata-se da instalação de esculturas flutuantes em forma de garrafas PET, confeccionadas em vinil num tamanho muito maior ao que esse artefato de consumo corresponde em seus usos convencionais (são 20 peças de 12 x 3,5 m cada peça). Atualmente, a obra participa da Bienal Internacional de Arte Contemporâneo da América do Sul (Bienal Sul) em diversas localidades da Argentina. Já ocupou o Rio Tietê (2008), a represa Guarapiranga (2010), o lago de Bragança Paulista (2012) e a praia de Santos (2014).

Figura 2: Fotografias de instalações referentes ao projeto PETS, do artista plástico paulistano Eduardo Srur.

\footnotetext{
${ }^{4}$ Disponíveis em: https://www.hometeka.com.br/f5/7-intervencoes-urbanas-do-artista-brasileiro-eduardo-srur/; http://www.eduardosrur.com.br/intervencoes/pets e http://www.eduardosrur.com.br/intervencoes/caiaques.

Rev. Eletrônica Mestr. Educ. Ambient. Rio Grande, Dossiê temático "Imagens: resistências e criações cotidianas", p. 430-449, jun. 2020. E-ISSN 1517-1256
} 


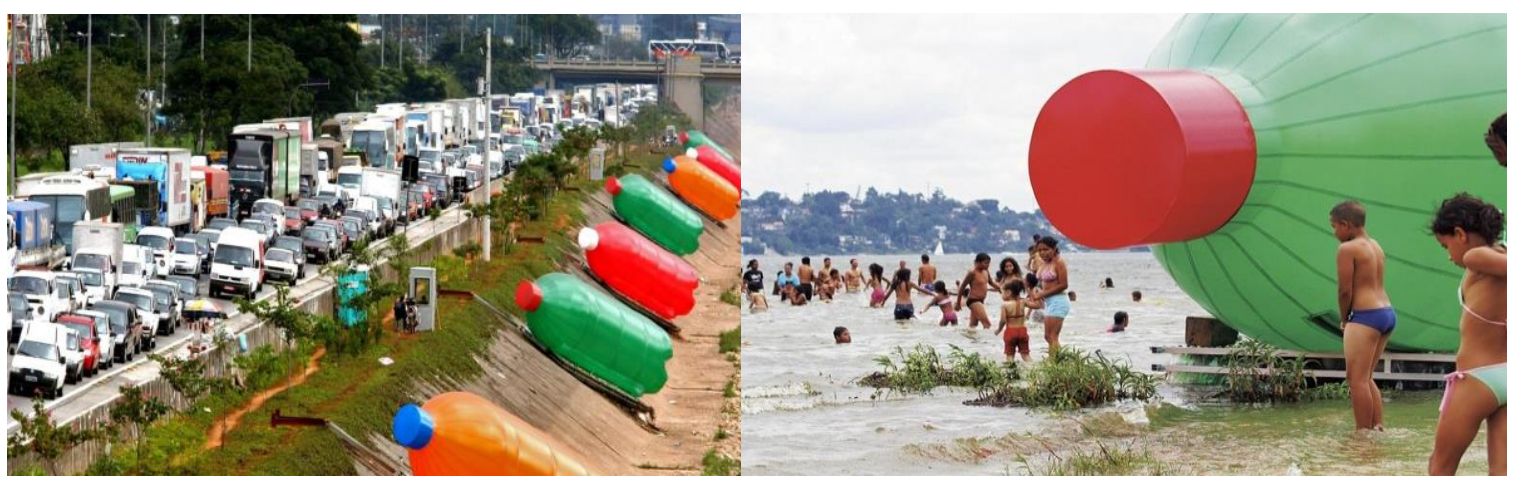

Fonte: https://www.hometeka.com.br/f5/7-intervencoes-urbanas-do-artista-brasileiro-eduardo-srur/; http://www.eduardosrur.com.br/intervencoes/pets e http://www.eduardosrur.com.br/intervencoes/caiaques.

A análise também contempla a obra Caiaques (Figura 4), que mantém o potencial de afectação democrático como ele mesmo se refere numa entrevista (CANTON, 2009). Nela, cento e cinquenta esculturas compostas por caiaques de plástico e remos de alumínio, manequins de plástico, roupas de tactel, parafusos e cabos de aço são lançadas a certa altura do rio Pinheiros, localizado na cidade de São Paulo. Não se detendo ao caráter de fixidez exigido em PETS, os caiaques boiam e transitam conforme o devir das águas. Um efeito estético curioso está demonstrado na segunda figura, em que as esculturas se aglomeram numa "ilha" de lixo superficial, acentuando contornos que muito remetem ao mapa do Brasil, um efeito não planejado pelo autor da obra.

Figura 4: Fotografias de instalações referentes à obra Caiaques, do artista plástico paulistano Eduardo Srur.

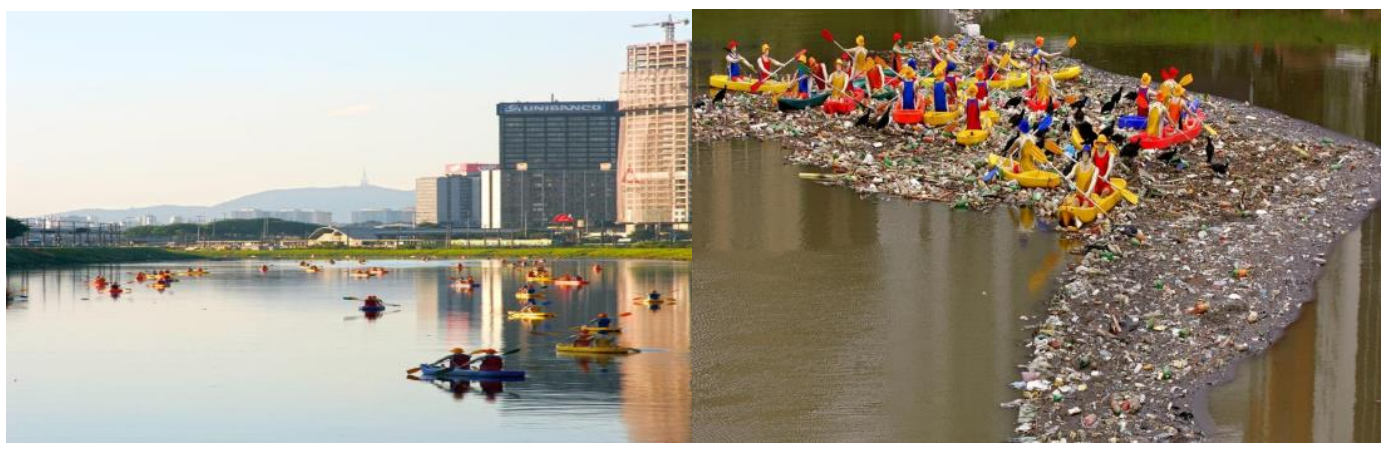

Fonte: http://www.eduardosrur.com.br/intervencoes/caiaques.

Que efeitos de sentido essas instalações e, até sua imprevisibilidade, puderam ser capazes de acionar em transeuntes, mas, também em nós, que podemos acessá-las pela

Rev. Eletrônica Mestr. Educ. Ambient. Rio Grande, Dossiê temático "Imagens: resistências e criações cotidianas", p. 430-449, jun. 2020. E-ISSN 1517-1256 
plataforma cibernética da internet? Novamente, que fugas ou rupturas estéticas mantem com a ecogovernamentalidade?

A escolha de Srur pela paisagem urbana encontra eco em Guattari (2012), que discute sobre o ethos estabelecido com os espaços urbanos. De acordo com esse autor, os cientistas já nos prediziam que, nos decênios que vivemos, cerca de $80 \%$ da população mundial viveriam em aglomerados urbanos e que mesmo os $20 \%$ restantes desta estatística seriam tributários ao habitat da cidade por meio de liames técnicos e de civilização. A preocupação, ao contextualizar esses dados, estaria no esmaecimento da distinção entre a cidade e a natureza, o que teria o efeito perverso da segunda subsistir em pequenos territórios "naturais", em meio a grande paisagem de concreto. Além disso, os grandes centros urbanos, como a região de São Paulo, acabam por dificultar singularidades individuais e coletivas, uma vez que foram simplificadas a espacialidades meramente facilitadoras do trânsito e do deslocamento das forças do Estado, à luz da biopolítica.

Nesta conformação, esses espaços incitam a "falsos nomadismos" (GUATTARI, 2012), uma vez que, no plano existencial, se permanece num mesmo lugar ${ }^{5}$. Se Foucault já situou o espaço como vetor imanente a seus elementos discursivos e não discursivos; Guattari complementa que, independente de qual seja o espaço, ele nos interpela a partir de diferentes pontos de vista: estilístico, histórico, funcional, afetivo... Nas suas palavras, "os edifícios e construções de todos os tipos são máquinas enunciadoras. Elas produzem uma subjetivação parcial que se aglomera com outros agenciamentos de subjetivação" (GUATTARI, 2012, p. 140). As cidades são megamáquinas, na expressão de Lewis Mumford, e, por isso, produtoras de subjetividades individuais e coletivas.

Assumindo esses efeitos, que enunciações produzem os grandes centros como São Paulo? Que feixes de subjetivação produzem, não apenas ela, mas inúmeras outras megalópoles globais características de nossos tempos? Antes de tudo, essas obras se perfilam entre as aglomerações urbanas de hoje, para as quais contam "menos os seus aspectos de infraestrutura, de comunicação e de serviço do que o fato de engendrarem, por meio de equipamentos materiais e imateriais, a existência humana sob todos os aspectos em que se queira considerá-las" (GUATTARI, 2012, p. 152). É porque a cidade continua a

\footnotetext{
${ }^{5}$ Os grandes centros urbanos são somente mais um dos componentes que, na modernidade exangue, garantem um deslocamento físico, mas nunca existencial. Em outro momento, o autor também dá o exemplo do turismo, "que se resume quase sempre a uma viagem sem sair do lugar, no seio das mesmas redundâncias de imagens e de comportamento" (GUATTARI, 2009, p. 8). Tanto no caso dos centros urbanos, quanto da prática do turismo, é a relação da subjetividade com sua exterioridade que está comprometida. Na redundância imanente a esses dois casos, a alteridade perde sua aspereza.
}

Rev. Eletrônica Mestr. Educ. Ambient. Rio Grande, Dossiê temático "Imagens: resistências e criações cotidianas", p. 430-449, jun. 2020. E-ISSN 1517-1256 
atualizar sua função de esquadrinhamento populacional - somada, também, à necessidade de trânsito de fluxos e informações do capitalismo pós-industrial - Guattari (2012) escreve esse texto, chamando a atenção para a necessidade de uma reorientação radical de seus meios que, se assim continuarem, culminarão em um estado de incompatibilidade total não apenas com a vida humana, mas animal e vegetal.

É nesse ínterim que a ecogovernamentalidade também incita escapes pelas vias de ressignificação ético-estéticas. Em meio à catástrofe (uma terminologia sinonímia para a crise) caracterizada pela velocidade com que os modos de vida são esvaídos, a sobrevivência (da humanidade, mas das outras formas de vida) novamente é posta em questão. É esta perspectiva que torna nossa época "aterrorizadora e apaixonante", haja vista que os fatores ético-políticos adquirem uma relevância que, ao longo da história, anteriormente jamais tiveram (GUATTARI, 2012, p. 152).

Quando Srur multiplica o tamanho das garrafas de refrigerante e as instala nas urbanidades estratégicas de passagem, ele possibilita um atravessamento no circuito cotidiano, um acontecimento que cria um possível. Nas suas palavras sua obra "[...] remete a um significado ecológico por sua forma e contexto na paisagem urbana contaminada"; deste modo, “[...] a apropriação e o jogo de escala de um ícone do consumo revela a complexa relação do homem com a natureza e uma provocação aos sentidos anestesiados no cotidiano urbano" (SRUR, 2019, s/p.). Em Caiaques, especificamente, ele declara que considerou " $[\ldots]$ a ideia de fazer esse resgate histórico do que era o rio, do que ele representava para a cidade e do que ele é hoje. Quando colocamos caiaques com manequins, há um caráter de provocação, estamos falando de uma coisa séria, mas há uma ironia" (CANTON, 2009, p. 58). A instalação dos 100 caiaques e dos 150 manequins, que começava na ponte das Bandeiras e ia até a ponte Eusébio Matoso também remeteu à ideia de "[...] fazer uma obra onde falta o ser humano, falta a consciência de preservação, de cuidado com o meio ambiente. Todas as minhas obras cada vez mais pensam numa mensagem direta para o espectador" (CANTON, 2009, p. 58-59).

Deste modo, PETS e Caiaques são "borrões" na estética da espacialidade da urbe. Deslocados de um lugar de suposta origem e fim - o mercado e o lixão, no caso das garrafas, uma represa limpa e não poluída, no caso dos caiaques - a própria instalação é uma poluição visual, mas no sentido incômodo que essas obras são capazes de causar aos nossos aparatos perceptivos. Romero (2018, p. 134) completa que, sob diversos nomes, intervenção urbana, arte participativa, colaborativa ou relacional - "a arte pode assumir um Rev. Eletrônica Mestr. Educ. Ambient. Rio Grande, Dossiê temático "Imagens: resistências e criações cotidianas", p. 430-449, jun. 2020. E-ISSN 1517-1256 
papel fundamental em relação à abertura de corpos e mentes a inéditas formas de se viver em contexto urbano".

Nesse sentido, as instalações consideradas nesse recorte analítico são capazes de anarquizar a cartografia espacial, pois operam por contradispositivos ${ }^{6}$ espaciotemporais. Em Roberta Carvalho, o tempo da lentidão, proporcionado pelo trajeto de barco, quebra a lógica acelerada do deslocar estéril da cidade. O espaço é apreciado: ao deslocar a luz para os rostos da população ribeirinha, o trajeto ganha tanta centralidade quanto o destino. Srur também desloca a noção de tempo-espaço em Caiaques, uma vez que, na atual conjuntura, apenas corpos de plástico "arriscam” um trajeto nas águas poluídas e inóspitas do rio Pinheiros. A instalação tensiona a memória de outro tempo, décadas anteriores, em que aconteciam atividades de remo promovidas pelos clubes paulistanos até a década de 1920 .

Os contradispositivos espaciotemporais, na acepção de Pelbart (2016, p. 269) contribuem como ficcionalização do real, e propõem "outras comunidades de palavras e de coisas, de formas e de significações" e, ao criar essas comunidades, "as imagens da arte não fornecem armas para os combates. Elas contribuem para desenhar configurações novas do visível, do dizível e do pensável, e por aí, uma nova paisagem do possível". Nesse enredar, a ficcionalização da realidade tem o mesmo efeito que uma ação política, pois funciona como uma política da percepção. Essa atividade seria inviável no momento presente, pois o rio está completamente contaminado, fruto do descaso da população e do governo, como termina sua descrição.

$\mathrm{Na}$ perspectiva analítica das máquinas estéticas, a heterogeneidade dos componentes que o mundo acena - linguísticos, corporais, espaciais - engendra, também, uma heterogênese ontológica. O "consumo" de certas obras é imanente à possibilidade de alargamento de pontos de vista, pois todo descentramento estético dos pontos de vista, toda multiplicação polifônica dos componentes de expressão passam pelo pré-requisito de uma “[...] desconstrução das estruturas e dos códigos em vigor e por um banho cósmico nas matérias de sensação, tornando possível uma recomposição, uma recriação, um enriquecimento do mundo, [...] uma proliferação não apenas das formas mas das modalidades de ser (GUATTARI, 2012, p. 105). Na perspectiva guattariana, as máquinas estéticas "nos propõem modelos relativamente mais bem realizados desses blocos de sensações suscetíveis de extrair um sentido pleno a partir das sinaléticas vazias que nos

\footnotetext{
${ }^{6}$ Como se tratam de um tipo de tecnologia que "responde" aos poderes totalitários da ecogovernamentalidade prefiro, neste contexto, o termo contradispositivo em vez de simplesmente dispositivo.

Rev. Eletrônica Mestr. Educ. Ambient. Rio Grande, Dossiê temático "Imagens: resistências e criações cotidianas", p. 430-449, jun. 2020. E-ISSN 1517-1256
} 
investem por todos os lados"; complementa, ainda, que são "nas trincheiras da arte que se encontram os núcleos de resistência dos mais consequentes ao rolo compressor da subjetividade capitalística" (GUATTARI, 2012, p. 105).

É por esse arraste de sensações que se considera as obras proponentes de uma ecologia do virtual, termo também cunhado por Guattari (2012), para se referir a formas outras de ecologias que se complementam às do mundo visível. São domínios que agregam a poesia, a música, as artes plásticas, buscando, nessas práticas sociais, acepções ampliadas em seu caráter plástico e performativo. Buscando complementar a ordem do prático e já existente, ela direciona suas preocupações às interfaces do sensível e das heterogeneidades.

Desse modo, o conjunto de tecnologias proposto por Carvalho e Srur ensejam outros tipos de máquinas que não aquelas ligadas à vigilância e ao controle, que caracterizam o aspecto de trânsito estéril e considera o meio como um mero ambiente de passagem. Elas propõem máquinas estéticas (GUATTARI, 2012) capazes de desterritorializar aquilo que se naturaliza nos aparatos ópticos e de engendrar subjetividades tão mutantes quanto a processualidade maquínica que incita a paisagem. Os artistas propõem um criar-se a si mesmos na imanência tecnológica, e não apenas num uso frio e mecânico.

\section{Considerações finais}

Os rostos de Roberta Carvalho e os mapas plásticos de Srur são capazes de tensionar dimensões existenciais de expressão, pois essas práticas estéticas arrastam consigo blocos de sensações. Blocos cuja função pode ser a de desmanchar as significações coladas às percepções triviais e as opiniões impregnando os sentimentos comuns. As obras consideradas no recorte analítico apresentado permitem pensar o meio ambiente para além dos dispositivos de segurança incitados pela ecogovernamentalidade.

Nas máquinas estéticas movidas pelas obras desses artistas, não há incitação a um "cuidado" do meio ambiente de maneira policialesca, como operam os dispositivos disparados pela agenda nacional que convoca à participação pela via da normalização de condutas. As máquinas também não se preocupam em atualizar preocupações capitalistas e implementar uma cultura de práticas para a resiliência, resiliência esta imanente à instituição de uma "tática de poder verde".

Rev. Eletrônica Mestr. Educ. Ambient. Rio Grande, Dossiê temático "Imagens: resistências e criações cotidianas", p. 430-449, jun. 2020. E-ISSN 1517-1256 


\section{Referências}

BARROS, Laura Pozzana de; KASTRUP, Virgínia. Cartografar é acompanhar processos. In. PASSOS, Eduardo; KASTRUP, Virgínia; ESCÓSSIA, Liliana da. Pistas do método da cartografia: Pesquisa-intervenção e produção de subjetividade. Porto Alegre: Sulina, 2015.

CANTON, Katia. Da política às micropolíticas. São Paulo: Editora WMF Martins Fontes, 2009.

CARNEIRO, Beatriz. A construção do dispositivo meio ambiente. Ecopolítica. V. 4. setdez, 2012. Disponível em: https://revistas.pucsp.br/ecopolitica/article/view/13057/9560. Acesso em 26/11/2016.

DELEUZE, Gilles. Conversações. São Paulo, ed. 34, 1992.

DELEUZE, Gilles. Foucault. São Paulo: Brasiliense, 2013.

DELEUZE, Gilles; GUATTARI, Félix. O que é a filosofia? 3. ed. São Paulo: Editora 34, 2010.

FOUCAULT, Michel. Os anormais. São Paulo: Martins Fontes, 2001.

FOUCAULT, Michel. As Palavras e as Coisas. 9. ed. São Paulo: Martins Fontes, 2007.

FOUCAULT, Michel. Segurança, Território, População. Martins Fontes: São Paulo, 2008.

FOUCAULT, Michel. As Técnicas de Si. In. FOUCAULT, Michel. Ditos e escritos, v. IX: genealogia da ética, subjetividade e sexualidade. (Organizado por Manoel Barros da Motta). Rio de Janeiro: Forense Universitária, 2014a.

FOUCAULT, Michel. História da sexualidade 1: A vontade de saber. São Paulo: Paz e Terra, 2014b.

GODOY, Ana. Conservar docilidades ou experimentar intensidades. in. PREVE, Ana Maria; CORRÊA, Guilherme (organizadores). Ambientes da ecologia: perspectivas em política e educação. Santa Maria: Editora da UFSM, 2007.

GODOY, Ana. A menor das ecologias. São Paulo: Editora da Universidade de São Paulo, 2008.

GUATTARI, Félix. Caosmose: um novo paradigma estético. São Paulo: Editora 34, 2012.

KASTRUP, Virgínia. O funcionamento da atenção no trabalho do cartógrafo. In. PASSOS, Eduardo; KASTRUP, Virgínia; ESCÓSSIA, Liliana da. Pistas do método da cartografia: Pesquisa-intervenção e produção de subjetividade. Porto Alegre: Sulina, 2015.

Rev. Eletrônica Mestr. Educ. Ambient. Rio Grande, Dossiê temático "Imagens: resistências e criações cotidianas", p. 430-449, jun. 2020. E-ISSN 1517-1256 
MALETTE, Sébastien. Foucault para o próximo século: ecogovernamentalidade.

Ecopolítica. v. 1. 2011 (p. 4-25). Disponível em:

https://revistas.pucsp.br/index.php/ecopolitica/article/view/7654. Acesso em 26/11/2016.

PELBART, Peter Pál. O avesso do niilismo: cartografias do esgotamento. 2. ed. São Paulo: n-1 edições, 2016.

PELBART, Peter Pál. Aos nossos amigos. in. RAGO, Margareth; GALLO, Sílvio. Michel Foucault e as insurreições: é inútil revoltar-se? São Paulo: CNPq, Capes, Fapesp, Intermeios, 2017.

PELBART, Peter Pál.Por uma arte de instaurar modos de existência que "não existem", 2017. Disponível em:

https://laboratoriodesensibilidades.wordpress.com/2017/05/02/por-uma-arte-de-instaurarmodos-de-existencia-que-nao-existem-peter-pal-pelbart/. Acesso em 30/07/2018.

PASSOS, Eduardo; KASTRUP, Virgínia; ESCÓSSIA, Liliana da. Pistas do método da cartografia: Pesquisa-intervenção e produção de subjetividade. Porto Alegre: Sulina, 2015 .

REIGOTA, Marcos; PRADO, Bárbara Heliodora Soares do (organizadores). Educação Ambiental: utopia e práxis. São Paulo: Cortez, 2008.

ROLNIK, Suely. Despachos no museu: sabe-se lá o que vai acontecer... in. RAGO, Margareth; ORLANDI, Luiz Lacerda; VEIGA-NETO, Alfredo (organizadores). Imagens de Foucault e Deleuze: ressonâncias nietzschianas. Rio de Janeiro: DP\&A, 2002.

ROLNIK, Suely. Esferas da insurreição: notas para uma vida não cafetinada. São Paulo: N-1 edições, 2018.

ROMERO, Manuela Linck de. Cartografias de experiências urbanas: corpo, pensamento e cidade em movimento. Curitiba: Appris, 2018.

SIQUEIRA, Leandro. Derivas siderais, ecopolítica e governamentalidade planetária. Ecopolítica. São Paulo. v. 15. 2016 (p. 2-36). Disponível em: https://revistas.pucsp.br/ecopolitica/article/view/28360/20571. Acesso em:22/08/2017.

VEIGA-NETO, Alfredo. Ecopolítica: um novo horizonte para a biopolítica. Revista Eletrônica do Mestrado de Educação Ambiental. V. Especial, dez/2014. Disponível em: https://periodicos.furg.br/remea/article/view/4860/3045. Acesso em: 22/08/2017.

Submetido em: 29-03-2020.

Publicado em: 01-07-2020.

Rev. Eletrônica Mestr. Educ. Ambient. Rio Grande, Dossiê temático "Imagens: resistências e criações cotidianas", p. 430-449, jun. 2020. E-ISSN 1517-1256 